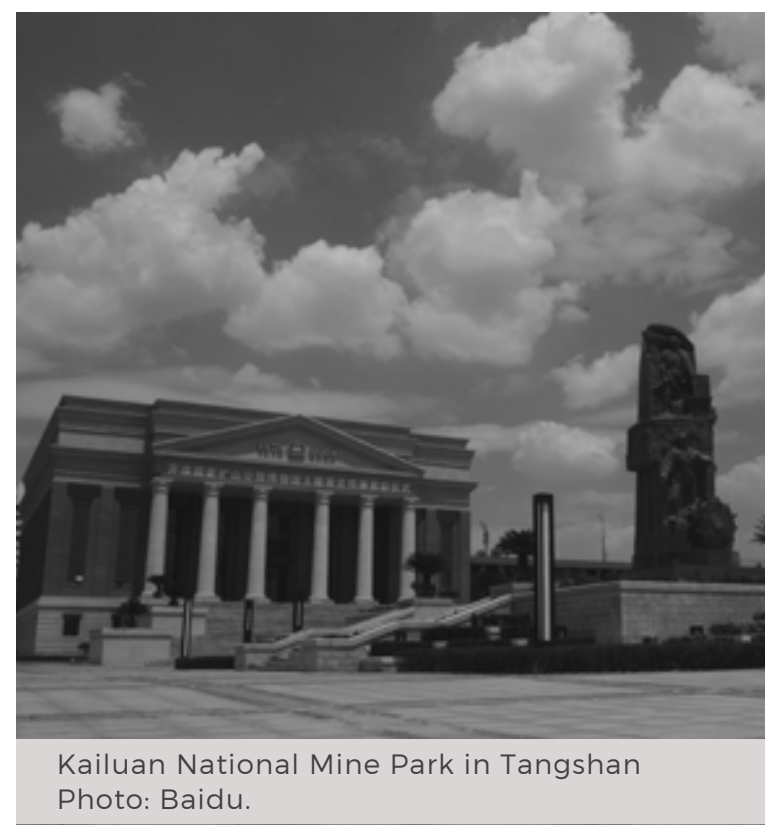

\section{Burning Coal in Tangshan: Energy Resources as Commons}

\section{Edwin Schmitt}

The extraction and use of energy resources to drive modernisation has been one of the key concerns of the Chinese Communist Party. By tracing the history of coal mining in China, this essay argues that the physical characteristics of coal as a common pool resource have shaped the ways in which coal has been harvested and used, as well as the political and institutional structures that have developed around its governance.
While it is not always well recognised, energy reserves are by far the most abundant and yet most conflict-ridden common resource. In this essay, I will look at the common pool of energy resources in China, specifically coal mining and coal-fired power plants. Perhaps the most famous description of the commons comes from Garrett Hardin's deceptively simple rendition: in order to prevent the ruin of common resources, society requires a set of rules for harvesting those resources so that they can be put to use. Originally the debate was about whether the most optimal rules could be found through a free market or a planned economy, the latter of which is the direction that China took. Elinor Ostrom provided a third insight into the debate, arguing that the form these rules could take was not that important as long as they were embedded into the everyday practices of a society.

Although he does not couch his argument in terms of the commons, Timothy Mitchell has recently argued that the physical characteristics of an energy resource has a strong relationship with the way these rules might develop and become socially embedded. According to Mitchell, democratic politics initially became entrenched in Europe during the Industrial Revolution as a result of the need for coal miners to collaborate together while deep underground to safely remove this energy resource from the earth. These strong collaborative relationships became essential when coal miners, as well as those responsible for transporting the coal from mine to factory, went on strike. The dense physical characteristics of coal allowed striking workers to ensure that the flow of energy, and therefore the flow of economic development, would grind to a standstill. This collaborative nature that emerged in the mines was a natural pairing with democratic politics when workers began to unionise and demand better conditions and pay from the capitalist owners of the mines. 


\section{The Early Democracy of Chinese Miners: Anyuan vs. Kaiping}

Mitchell's history of coal begs the question: why did similar democratic principles not emerge among coal miners in China? In some ways they did, at first. One of the most famous examples comes from the Anyuan Mines, Jiangxi province during the 1920s where the Chinese Communist Party (CCP) planted the seeds of the Communist Revolution. It was the collaborative nature of the miners that allowed the Party to develop Anyuan into a kind of 'worker's university' for disseminating strategies for unionising and calling worker strikes around China. Many of the principles practiced at Anyuan were rooted in democratic principles of equality while, of course, also being embedded within a Marxist-Leninist ideological call for class struggle. After attacks by the Kuomintang, the workers were forced to abandon the mine but ended up forming the First Red Army of China. As we will see, this militarisation of the workers had consequences for why China's coal miners eventually organised in a manner that does not fit Mitchell's narrative.

While the miners in Anyuan were initially democratic, workers at the Kaiping Mines in Tangshan, located in Hebei province, were suppressed by a capitalist and colonialist system of exploitation. Most of China's early industrial labour force was recruited from rural populations far from industrial centres. It was up to a group of labour contractors (batou) to bring workers and owners together, but this created an effective barrier that often prevented the British owners of the mine from ever hearing the needs of their workforce. A strict hierarchy at Kaiping ensured that the rules and decisions made for governing the mining of coal received little or no input from those labouring to remove the energy source from the earth.
In late 1948, Tangshan was 'liberated' from the rule of the Kuomintang by an elite unit of the People's Liberation Army (PLA). As a first order of business, two high-ranking officers, Li Chenglong and Yan Dakai, respectively took control of the Tangshan Electric Plant and the Kailuan Coal Mine (the new name for the Kaiping mines). At that stage, it was imperative for the PLA to quickly revive the productive forces that would ensure a stable supply of weaponry to the military. Tangshan was not only a centre of energy production, but it also produced military vehicles needed to keep the PLA mobile as the CCP cemented its power across China. Since there were no CCP members at the power plant, Li Chenglong spent the first two years focussed on indoctrinating the plant workers into a socialist mode of production. While workers were considered equal 'owners' of the plant, Li installed a new hierarchy for organising decision-making, by establishing worker's brigades that had to answer to their brigade leaders, who in turn had to answer to the plant leader. This institutional hierarchy, mimicked that found within the PLA.

Moreover, scientific and engineering brigades were established, so that educated elites were integrated into the decisionmaking process of the plant. Regarding energy production, the plant leader took the input of scientists and engineers quite seriously. While the plant leader oversaw day-to-day decisionmaking, the amount of energy produced and supplied to the electrical grid was a decision made by the Tangshan Electrical Bureau in consultation with the goals established by the Ministry of Water Conservancy and Electric Power of Hebei province and the Central Government. While this was certainly a new hierarchy, the fact that decisions on these matters were being made far away from the plant was nothing new to the workers. Similar processes were taking place at the Kailuan mine as well. 


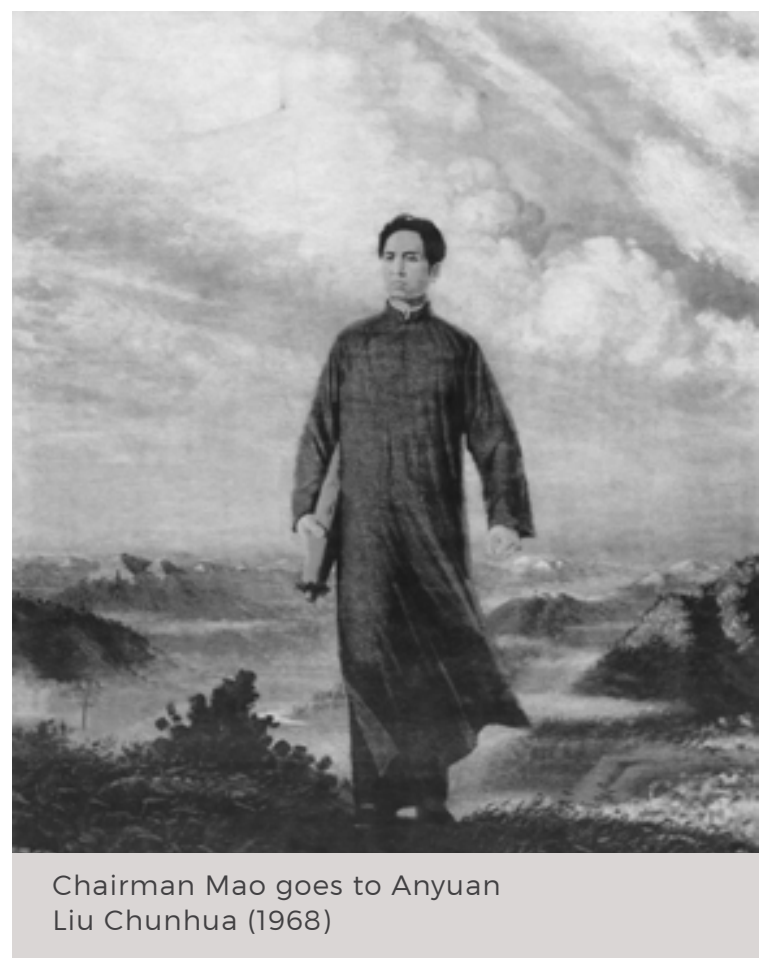

\section{The Rise of Chinese Unions}

One major difference with the hierarchy found in the older batou system was the establishment of the worker's unions. Although it was a country-wide union in name, the official All-China Federation of Trade Unions (ACFTU), was hardly a monolithic entity across China. At the grassroots level, both the Kailuan Coal Mines and Tangshan Electric Plant established unions that represented the workers of their respective facilities. These unions allowed the voice of the workers to be heard within the Party and could be considered an outgrowth of the ideas that developed during the Party's time at Anyuan. Throughout the first thirty years of the People's Republic of China (PRC), the unions created a certain level of antagonism that required the military hierarchy described above to cooperate with the workers through their union leaders. Moreover, the transmission of Party ideology was dependent on the unions and in some cases this would result in situations beyond the control of the plant leader. For instance, during the second Anti-Rightist Campaign of 1959, the workers forced Plant Leader Li Bin to resign and heavily criticised him for his supposed rightist positions regarding electricity production. It was not until 1962 that he was forgiven, eventually becoming the plant leader for the duration of the Cultural Revolution. However, there were also times throughout the Great Leap Forward (19581962) and Cultural Revolution (1966-1969) when ideological shifts provided the plant leader with exceptional power and forced the workers to commit to dangerous production quotas leading to multiple accidents.

In other words, while a new hierarchy was put into place that still provided a degree of separation between the workers and decisions for harvesting and utilising energy resources, there was always a struggle between a group of decision-making experts and the workers. Perhaps the potential for a more democratic power structure did exist in early PRC history. However, we should also keep in mind that the workers' unions were isolated within their work unit. The union at Kailuan Coal Mine was strictly focussed on providing a voice for the miners and had no control over where the coal mined from Kailuan would end up. The only real connection between the Kailuan Coal Mine and the Tangshan Electric Plant unions would be when the chairperson of the union or a few worker representatives might meet at the Hebei Provincial Worker's Union Annual Conference.

Multiple worker unions never collaborated, which is why the idea of a sector-wide strike preventing the flow of energy resources was unthinkable. In some ways, we might even argue that the ability of the state to ensure the flow of energy from the common pool of resources into the economy was at least as effective in this socialist military hierarchy as it ever was within the capitalist economies of Europe. Perhaps we could say that the institutionalisation of a military hierarchy for organising energy resource management that 
included the ability of the union to provide workers with a voice was somewhat similar to the nested institutions described by Ostrom.

\section{A Model for Energy Management}

Over the years, Tangshan's energy production was presented as an institutional model to the rest of the country, not unlike the more (in)famous Daqing Oil Fields. Books were distributed to coal-fired power plants around the country with titles like 'The Situation of Tangshan Electric Plant Cadres Participating in Labour'. Both the Tangshan Electric Plant and the Kailuan Coal Mine regularly graced the pages of the People's Daily, with the latter being praised for its success at implementing cutting-edge technology in removing coal from the earth. More recently, the messages have begun to shift after a plan to expand the plant was accused of violating environmental policies in 2007. Today, both the Kailuan Mine and the Tangshan Electric Plant have been shut down and turned into parks, similar to those discussed by Maris Gillette in this issue (see p. 25). Just a year ago, the People's Daily even published a detailed article about the successful remediation process taking place at Kailuan Coal Mine. Even in 'death', the mine and the power plant are being used as examples to follow as China enters the new historical phase of 'Ecological Civilisation' (shengtai wenming).

Naturally, the top-down nature of Ecological Civilisation that ensured the decision to close the plant and mine had little to do with what the workers themselves wanted. What is ironic about this story is that the top-down hierarchical political structure from which the Ecological Civilisation ideology emerged originated with the need to ensure that the Chinese military had access to highly polluting energy resources, such as coal. Regarding the commons, we can see that a top-down method can be used to prevent access to common energy resources just as it can organise the harvest of them. My focus here has not been on the effectiveness of this hierarchical structure to manage those resources over the long term-others have already argued that it did a very poor job. Instead, I have been trying to show how a certain kind of social structure and political decision-making emerged from the hierarchical rules for governing commonpool energy resources in China. While some aspects of democratic decision-making did find their way to China's coal fields, the bonds between coal miners that Mitchell described in the European context were prevented from developing into a true political force because of the institutional structure of the CCP. In other words, the material aspects of the environment are not ineffectual when it comes to the rules we devise for governing the commons, but nor do they solely determine the structure of those rules or the political power needed to enforce them.

\section{Edwin Schmitt}

Edwin Schmitt is a Postdoctoral Researcher at the University of Oslo. In the past, he has conducted ethnographic and survey-based research on environmental consciousness in the city of Chengdu. His current project aims to examine how the production of energy has been connected to the formation of, and changes within, the broader political power structures in recent Chinese history. 